\title{
Post-transcriptional regulation in cancer progression
}

\author{
Microenvironmental control of alternative splicing and translation
}

\author{
Michael Jewer • Scott D. Findlay • Lynne-Marie Postovit
}

Received: 11 July 2012 /Accepted: 24 September 2012 /Published online: 9 October 2012

(C) The International CCN Society 2012

\begin{abstract}
The microenvironment acts as a conduit for cellular communication, delivering signals that direct development and sustain tissue homeostasis. In pathologies such as cancer, this integral function of the microenvironment is hijacked to support tumor growth and progression. Cells sense the microenvironment via signal transduction pathways culminating in altered gene expression. In addition to induced transcriptional changes, the microenvironment exerts its effect on the cell through regulation of posttranscriptional processes including alternative splicing and translational control. Here we describe how alternative splicing and protein translation are controlled by microenvironmental parameters such as oxygen availability. We also emphasize how these pathways can be utilized to support processes that are hallmarks of cancer such as angiogenesis,
\end{abstract}

Summary Classically, the influence of the tumor microenvironment on the regulation of cellular phenotype has been assessed principally in terms of changes in gene expression at the level of transcription. Here, we detail evidence of an integrated response that also involves control of alternative splicing and protein translation, collectively contributing to tumor progression.

Michael Jewer and Scott D. Findlay are co-first authors.

Michael Jewer, Scott D Findlay, and Lynne-Marie Postovit all agree to submit this article to the Journal of Cell Communication and Signaling. This work was supported by the Canadian Institutes for Health Research (MOP 89714, MOP 119589, and PLS 95381) and the Cancer Research Society to L.-M. Postovit. S.D. Findlay is the recipient of a scholarship from the Natural Sciences and Engineering Research Council of Canada (NSERC). M. Jewer is the recipient of a Canadian Institutes of Health Research (CIHR) scholarship. L.-M. Postovit is the recipient of the Premier New Investigator Award from the CIHR.

The authors confirm independence from the sponsors; the content of the article has not been influenced by the sponsors.

M. Jewer $\cdot$ S. D. Findlay $\cdot$ L.-M. Postovit $(\bowtie)$

Department of Anatomy \& Cell Biology, The Schulich

School of Medicine and Dentistry, Western University,

438 Medical Science Building,

London, ON N6A 5C1, Canada

e-mail: Lynne.Postovit@schulich.uwo.ca proliferation, and cell migration. We stress that cancer cells respond to their microenvironment through an integrated regulation of gene expression at multiple levels that collectively contribute to disease progression.

Keywords Tumor microenvironment · Alternative splicing · Translation · Cancer progression

\section{Introduction}

Cellular phenotypes are tightly regulated by molecular signals such as oxygen gradients and growth factors that collectively constitute the microenvironment. This microenvironment provides the extracellular cues for growth, differentiation, and death throughout the lifespan of a cell. However, if a cell accumulates sufficient mutational and epigenetic changes, it may become aberrantly insensitive to anti-proliferative cues, or itself contribute pro-proliferative signals to the microenvironment. Both of these aberrant processes can result in uncontrolled cell division and ultimately cancer. Thus, normal physiology depends on dynamic interplay between a cell and its microenvironment, with disruption potentiating tumor initiation and progression toward metastatic disease.

In cancer, an altered microenvironment provides a context similar to that of early embryonic development, marked by the presence of pro-proliferative growth factors and hypoxic growth conditions. Consequently, some tumor cells can acquire embryonic-like phenotypes characterized by an increased potential for proliferation and survival. Classically, molecular components and changes mediating such processes have been assessed in terms of epigenetic alterations potentiating changes in gene transcription (Postovit et al. 2008). However, it is now becoming apparent that numerous levels of post-transcriptional regulation are also integral to the tumor cell response to the microenvironment. This review will focus on alternative pre-mRNA splicing and translational control as 
two major points of post-transcriptional regulation mediating tumor progression in response to the microenvironment. Analogous to "turning on" and "turning off" genes through transcriptional regulation, control over alternative splicing dictates which transcript (often with strongly divergent or opposing functions) will be expressed from a single gene. Control over translation dictates which transcripts are translated under different contexts, often independent of transcript abundance, as the global correlation between transcript and corresponding protein is only moderate (e.g. Schwanhausser et al. 2011) (Fig. 1).

\section{Alternative splicing}

Mechanisms of alternative splicing (AS) exist for many genes whereby different combinations of exons within a single pre-mRNA can be included in distinctly processed transcripts that serve as substrates for translation. Recent genome-wide analyses suggest that AS might affect as many as $95 \%$ of multi-exon human transcripts (Wang et al. 2008). The relative positions of utilized $5^{\prime}$ donor and $3^{\prime}$ acceptor splice sites are used to classify different types of AS events as cassette alternative exon, mutually exclusive exon, alternative $5^{\prime}$ splice site, alternative $3^{\prime}$ splice site, or intron retention (Fig. 2). This newfound appreciation of the ubiquity of AS suggests there are numerous alternatively spliced transcript isoforms yet to be characterized.

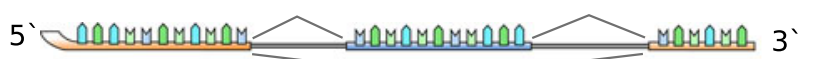

Cassette Alternative Exon

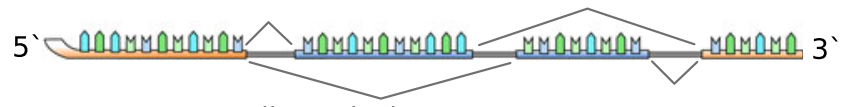

Mutually Exclusive Exon

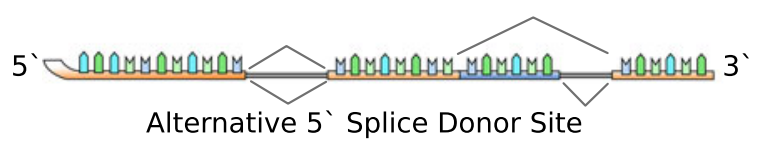

Alternative $3^{\prime}$ Splice Acceptor Site

Fig. 2 Major types of alternative splicing. Orange bars represent constitutive exons always included in the processed mRNA transcript. Blue bars represent alternative exons, and grey bars represent introns. Diagonal lines join splice donor sites at the $5^{\prime}$ end of an intron and splice acceptor sites at the $3^{\prime}$ end of an intron, flanking the intronic sequence to be spliced out. Splicing sites along the top of the transcript denote one possible transcript, while those along the bottom denote the other isoform for these simple cases

How is splicing altered in cancer?

As is true for gene transcription, patterns of AS also differ among adult tissues such as brain, skeletal muscle, breast, liver, and colon. For example, only $2 \%$ of processed transcripts for the tropomyosin 1 (alpha) gene (TPM1) contained exon 2 in heart tissue, while in skeletal muscle

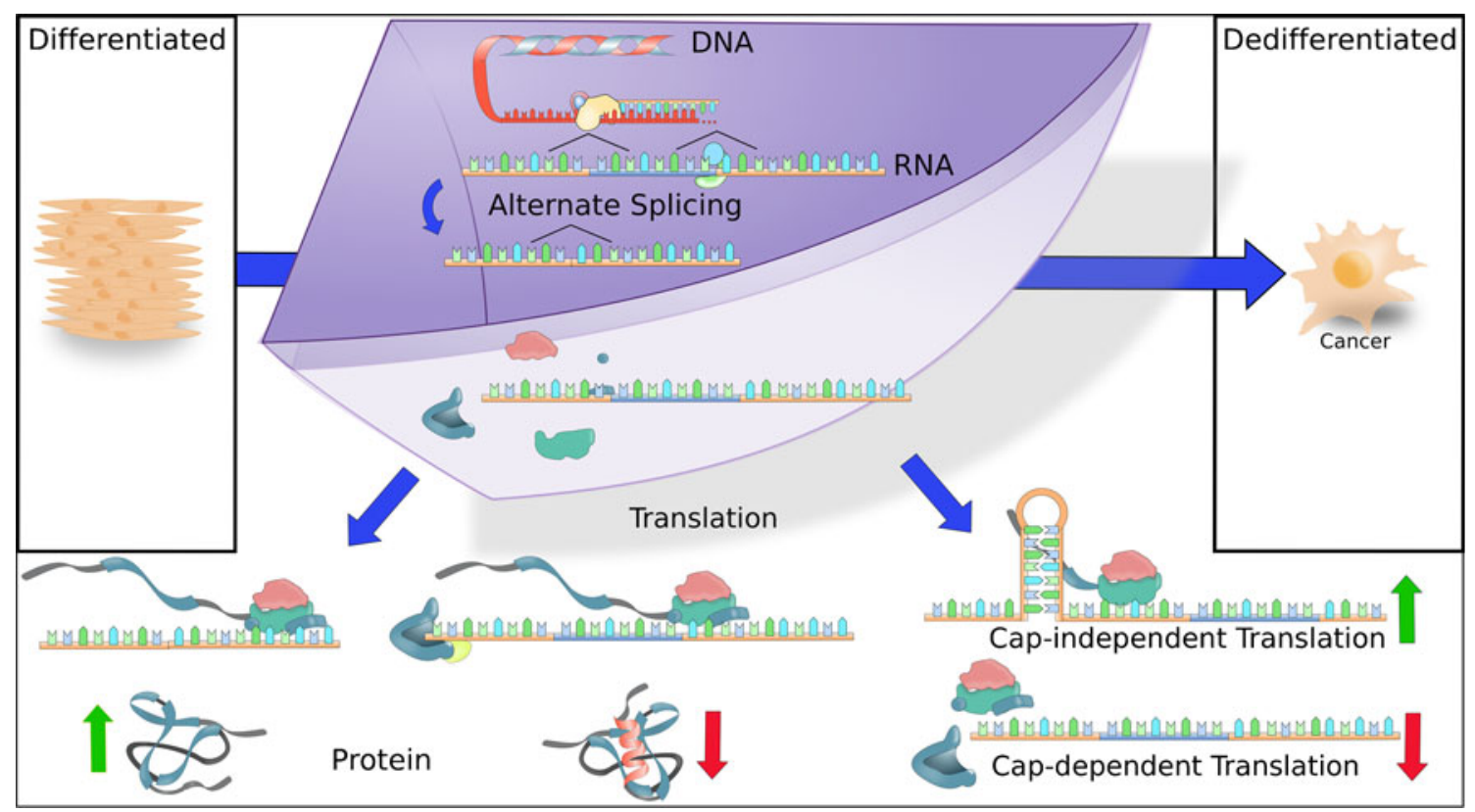

Fig. 1 A schematic of how fate decisions are regulated in part by microenvironmental factors. The large blue horizontal arrow represents how differentiated cells can become dedifferentiated during tumorigenesis. This process involves cellular responses to the microenvironment that include changes in transcription, as well as post-transcriptional processes such as alternative splicing and translation. An example in which expression of one protein isoform is increased (green arrow) and the alternatively-spliced isoform is decreased (red arrow) is shown 
such transcripts accounted for $95 \%$ of all TPM1 spliced (Wang et al. 2008). It follows that AS is tightly regulated over the course of development, and that specific patterns of splicing must be maintained in adult tissues to preserve distinct cellular identities and functions. Unsurprisingly, much like transcriptional regulation of gene expression, control over AS is commonly deregulated in cancer and has been the focus of several excellent reviews (David and Manley 2010; Fackenthal and Godley 2008; Srebrow and Kornblihtt 2006; Watermann et al. 2006).

Altered AS can contribute to cancer progression in different fashions. First, mutations or polymorphisms within a splice site motif such as a $5^{\prime}$ splice site donor or a $3^{\prime}$ splice site acceptor can result in altered splicing of transcripts transcribed from the affected locus. For example, in breast and ovarian cancer, mutations in the tumor suppressor breast cancer 1, early onset (BRCA1) often disrupt constitutive splice sites, leading to the production of isoforms that cannot translate functional protein (Thomassen et al. 2011). Second, the regulation of particular AS events can become generally disrupted due to widespread genetic, epigenetic, and post-transcriptional changes associated with malignant transformation and spread. Notably, such disruption is not necessarily directly related to mutation status of the affected transcript(s). For example, exposure of primary epithelial cells to insulin growth factor 1 (IGF1) and tumor necrosis factor alpha (TNF- $\alpha$ ) promotes increased splicing of pro-angiogenic vascular endothelial growth factor A (VEGFA or VEGF) $\mathrm{VEGF}_{\mathrm{xxx}}$ isoforms relative to the anti-angiogenic $\mathrm{VEGF}_{\mathrm{xxxb}}$ isoforms. Thus any ectopic activity of these growth factors in cancer likely contributes to enhanced tumor angiogenesis in part through a specific AS change (Nowak et al. 2008).

Interestingly, the potential also exists for alternative splicing to modulate protein structure through the inclusion or skipping of exon(s), in cases where each exon encodes for a distinct protein domain. Indeed this is the case for the $\mathrm{CCN}$ proteins, with characteristic signal peptide (SP), insulin growth factor binding protein-like (IGFBP), Von Willebrand type $\mathrm{C}$ repeat (VWC), thrombospondin (TSP1) and Cterminal cysteine knot (CT) domains each encoded by individual exons. Alternatively spliced transcripts of this nature have been identified for CCN1, CCN3, and CCN4 (Perbal 2009). These transcript variants have been identified in pathologies such as scirrhous gastric carcinoma, cholangiocarcinoma, hepatoma, Ewing's tumors, Wilm's tumors, and human breast tumors. How these transcripts may contribute to cancer pathology is the focus of an excellent review (Perbal 2009). One interesting example of such splicing is found in a study by Tanaka and colleagues focused on CCN4 (WISP1), a protein implicated in fibrosis. RT-PCR of gastric carcinoma tissue samples revealed a novel WISP1 transcript, designated WISP1v. This smaller transcript variant was detected in the majority of scirrhous type gastric carcinoma ( $86 \%$ of samples) associated with a poor prognosis, but in few of the non-scirrhous gastric carcinoma samples (15\%), and patientmatched normal adjacent mucosa samples (Tanaka et al. 2001). Sequence analysis revealed this transcript resulted from skipping of exon 3 which encodes the VWC domain in full length CCN transcripts. Transfection of NIH3T3 fibroblasts with either WISP1 or WISP1v revealed enhanced cellular transformation, more rapid cellular growth, as well as increased migration of gastric carcinoma cells in co-culture, for fibroblasts transfected with the novel WISP1v relative to those transfected with canonical WISP1 (Tanaka et al. 2001).

CCN1 (Cyr61) offers a mechanistically distinct example of how a change in AS can promote tumor progression. CCN1 promotes cell proliferation, migration, and adhesion (Kireeva et al. 1996), as well tumour angiogenesis (Babic et al. 1998) and is of great interest in breast cancer, where its expression is positively correlated with both disease stage and positive lymph nodes (O'Kelly et al. 2008). Hirschfeld and colleagues demonstrated the existence of a $\mathrm{CCN} 1$ transcript variant wherein intron 3 is retained in the processed transcript. Interestingly, this isoform was shown to be the predominant CCN1 transcript in noncancerous normal tissue, with little canonical CCN1 detected. However, in patient-matched samples of primary adenocarcinoma of the breast, roughly equal levels of the intron-retaining and canonical intron-skipping transcripts were observed (Hirschfeld et al. 2009). Since there are two stop codons within the third intron and in the translational reading frame, the authors hypothesize that the intronretaining isoform likely triggers nonsense-mediated decay (NMD), a process that contributes to transcript degradation and limited protein expression, typically when stop codons are present more than 50 nucleotides upstream of an exon-exon junction (Gardner 2010). Thus, alternative splicing actively maintains $\mathrm{CCN} 1$ expression at sub-pathogenic levels in normal adult tissue. In cancer, this regulatory mechanism is lost, leading to the productive translation of the canonical tumorigenic isoform (Hirschfeld et al. 2009). Although NMD is the most likely result of intron-retaining CCN1 splicing, the authors did not consider the possibility that the intronretaining isoform of CCN1 mRNA might translate to a protein product in which only the SP, IGFBP, and VWC domains are present due to the premature termination codon upstream of the fourth exon. The existence of such an isoform would be exciting and is worthy of exploration, as has been mentioned previously (Perbal 2009).

Beyond CCNs, the global collection of AS events altered in cancer contribute to many pathological processes such as evasion of anti-tumor immunity (largely concerning apoptosis), alterations in metabolism, invasion and metastasis, epithelial to mesenchymal transition (EMT), angiogenesis, and translation of oncogenic protein isoforms (reviewed in David and Manley 2010). In an interesting metabolic example, the splicing of an embryonic form of pyruvate kinase known as 
PKM2, allows cancer cells to undergo aerobic glycolysis, a process thought to be essential in meeting biosynthetic demands in a highly proliferative tumor. In contrast, normal differentiated cells perform aerobic glycolysis at much lower rates owing to splicing of the PKM1 isoform (Christofk et al. 2008). Dysregulation of AS is widespread in cancer, occurring in pathways related to the original six (and now more numerous) "hallmarks of cancer" described by Hanahan and Weinberg (Hanahan and Weinberg 2000, 2011), and thus may present opportunities for therapeutic intervention and novel prognostic biomarker identification for specific cancers (Dales et al. 2010; Huang et al. 2007).

\section{Translational control}

As the greatest expenditure of energy in the cell is protein synthesis, it is fitting that translation is tightly regulated. The rate limiting step of translation and the point of tightest regulation is initiation (Gingras et al. 2001). Initiation requires the coordination of multiple proteins, named eukaryotic initiation factors (eIFs). eIFs are required for recognition of the $\mathrm{m} 7 \mathrm{GpppN}$ cap, recruitment of the ribosome, and ribosomal positioning at the translational start site (Mamane et al. 2006). Translation initiation is reduced during conditions of stress. eIFs like eIF4E and eIF $2 \alpha$ have their function inhibited by stress pathways like the mTOR pathways and stress signals from the ER. Because of the central role of translation in cellular physiology, it is not surprising that it is critical in development, differentiation, cell cycle progression, and apoptosis (Gingras et al. 2001). Alterations to the proteome that initiate from changes in translation occur faster than changes that require transcription by circumventing the need to produce and export transcripts from the nucleus (Gingras et al. 2001). The rate of the translational response and the extent to which it can change expression patterns and conserve energy, gives translation a central role in responding to the microenvironment.

How is translational control altered in cancer?

Two themes permeate the role of translation in cancer. The first theme is that in times of stress, cancer cells will limit translation to a subset of proteins that broadly promote survival, consequently causing a more aggressive cancer. The second theme is that increases in the proteins required to initiate translation, eIFs, release important modulators of the cell cycle leading to uncontrolled growth (Li et al. 2003, 2004b; Mamane et al. 2006; Tan et al. 2000).

Microenvironmental factors are primarily responsible for activating the translational stress response. Cells in internal regions of a tumor often lack the local vasculature necessary to deliver nutrients and oxygen. Such cells become stressed, triggering a decrease in global rates of translation in order to maintain energy homeostasis. One of the most potent mediators of this conservation is hypoxia (Liu et al. 2006; Wouters and Koritzinsky 2008). Two mechanisms are responsible for ensuring the decrease in translation observed during stress. First, phosphorylation of eIF $2 \alpha$ in response to endoplasmic reticulum stress causes eIF $2 \alpha$ to remain bound to GDP; In this inactive state, recognition of the start site of translation is prevented. Multiple pathways can inactivate mammalian target of rapamycin (mTOR) which leads to the dephosphorylation and activation of eIF $4 \mathrm{E}$ binding protein (4E-BP), a translational repressor. 4E-BP binds to eIF4E preventing the formation of the cap-binding complex. Without eIF4E the translational complex cannot identify the $5^{\prime}$ cap (Young et al. 2008). Under stress, cap-dependent translation is suppressed. This process conserves valuable energy while inducing an adaptive stress response, such that transcripts encoding proteins required for survival can still recruit ribosomes by means of internal ribosome entry site (IRES) sequences in their 5'UTRs (Young et al. 2008).

Various changes in translation initiation have been demonstrated to have broad effects on pathogenicity. Early work showed that many individual eIFs are up-regulated in cancer and that these changes correlate with cancer progression (Eberle et al. 1997; Kerekatte et al. 1995; Li et al. 1997; Miyagi et al. 1995). These findings were expanded by the use of global microarray analyses of multiple tumor types which found a strong correlation between the amount of eIF4E and the expression of both the pro-angiogenic factor VEGF, and the cell cycle protein cyclin D1 (Yang et al. 2007). Other eIFs have been shown to be deregulated in cancer and have been reviewed extensively (Yin et al. 2011).

The activity of mTOR has also been correlated with malignancy in melanoma and prostate cancers (Karbowniczek et al. 2008; Pópulo et al. 2010). Furthermore, many cancers have been shown either clinically or experimentally to be responsive to mTOR inhibitors (summarized in Mamane et al. 2006). Increased mTOR activity disrupts proper control of translation by inactivation of 4E-BP. An increase in the phosphorylation of 4E-BP has been clearly correlated with survival in patients with cancers such as melanoma (O'Reilly et al. 2009). Inactivation of 4E-BP via phosphorylation prevents it from binding eIF4E, maintaining a high level of cap-dependant translation. Similarly, over-expression of 4E-BP has been shown to reduce tumorigenesis and growth (Rousseau et al. 1996). 4E-BP can even compensate for transformation caused by increased levels of eIF4E (Avdulov et al. 2004). Further evidence for the importance of translational regulation was found by expressing constitutively active 4E-BP mutants in U2OS osteosarcoma cell lines. Cell size and cell cycle progression could be regulated by the 4E-BP mutant, as the mutant phenotypes mimicked those caused by treatment with rapamycin (Fingar et al. 2002, 2004). 
Regulation of translation is important for maintaining the balance between apoptotic and cell survival signals (Mamane et al. 2006). eIF4E increased chemoresistance and decreased apoptosis in fibroblasts with constitutively expressed c-myc, primarily through increasing the rate of cyclin D1 translation (Tan et al. 2000). Li and colleagues showed that the reduction of eIF4E decreased cytochrome $\mathrm{c}$ release and endoplasmic reticulum-mediated apoptosis, implicating the increased translation of $\mathrm{Bcl}-\mathrm{X}_{\mathrm{L}}$ as part of the mechanism (Li et al. 2003). Similar experiments utilizing antisense oligonucleotides to knock down eIF4E in MDAMB-231 cells decreased another Bcl protein, Bcl-2 (Graff et al. 2007). The many roles eIF4E has in the progression of cancer, the frequency of its up-regulation, and its transforming potential in NIH $3 \mathrm{~T} 3$ cells have identified it as a protooncogene (Lazaris-Karatzas et al. 1990). eIF4A1, a well studied RNA helicase, has also been implicated in several cancers including melanoma, hepatocellular carcinoma, and early stage non-small cell lung cancer (Eberle et al. 1997; Shuda et al. 2000; Wang et al. 2002). To assess the direct effect of eIF4A1 on Bro and SKM13 melanoma cell lines, each line was transfected with vectors including inducible eIF4A1 antisense RNA. Using thymidine incorporation rates to measure proliferation, Eberle et al. demonstrated that eIF4A1 expression is positively correlated with proliferation in melanoma cell lines. The mechanism for this increase in proliferation is unknown but similar experiments evaluating the effects of expression of another eIF, eIF $2 \alpha$, demonstrated an upregulation of cyclin D1 (Rosenwald et al. 2003). Thus, altered translational regulation can greatly affect proliferation.

\section{Signaling from the microenvironment}

Combinatorial induction of AS and translational responses

A major hallmark of cancer is the acquired ability to sustain growth and survival while adapting to alterations in the microenvironment. This is achieved largely through aberrations in key signaling pathways that link extracellular growth factors with intracellular signaling cascades that modulate gene expression and other cellular processes. Indeed, AS and translational control are susceptible to dysregulation via these dysfunctional signaling pathways, and represent additional mechanisms through which tumor growth and survival are achieved.

\section{Microenvironments affecting splicing}

A role for tumor-associated signaling in the regulation of AS in developmental pathways is emerging. Notch is a transmembrane receptor that binds members of the Delta-like and Jagged families of ligands expressed on the surface of adjacent cells.
Ligand binding results in cleavage of the Notch Intracellular Domain (NICD) and subsequent activation of CSL family transcription factor complexes, affecting transcription of genes such as Myc, Cyclin D3, and p21, thus affecting decisions pertaining to cell fate. In addition to direct canonical transcriptional targets, Notch signaling can also indirectly affect AS. For example, constitutive Notch signaling is known to promote leukemogenesis in T cell acute lymphoblastic leukemia. One mechanism by which this is achieved is through Notchdependent increased splicing of a non-DNA binding and dominant negative isoform of the transcription factor Ikaros, also implicated in leukemogenesis (Bellavia et al. 2007).

Extracellular ligands of the transforming growth factorbeta (TGF- $\beta$ ) superfamily help establish the body plan during development by initiating signaling cascades that regulate differentiation, migration, and proliferation. Generally, TGF$\beta$ signals through serine/threonine kinase receptors at the cell surface resulting in subsequent activation of specific SMAD proteins that mediate changes in gene expression through interaction with various transcription factors. TGF- $\beta$ signals affect splicing of several transcripts in normal cellular contexts (Chang et al. 2004; Martin et al. 2006). In cancer, regulation of splicing events by TGF- $\beta$ is consistent with the notion that this ligand can act as both a tumor suppressor as well as key component in the progression of cancers. TGF- $\beta$ has been shown to potentiate the fibroblast growth factor receptor (FGFR) splice switch associated with cancer progression in a mouse mammary epithelial model of EMT (Shirakihara et al. 2011), but also preferentially splices anti-angiogenic $\mathrm{VEGF}_{\mathrm{xxxb}}$ isoforms which are down-regulated during the progression of many tumors (Nowak et al. 2008).

Signaling converges on "splicing hubs"

The effects of growth factors and other components of the microenvironment on AS are mediated by intracellular signaling cascades ( $\mathrm{Li}$ et al. 2004a; Stamm 2002). These cascades ultimately affect splicing regulatory proteins such as members of the SR and heterogeneous nuclear ribonucleoprotein (hnRNP) families (David and Manley 2010; Lynch 2007). Two "splicing hubs" through which a multitude of cascades converge to regulate AS have been identified as hnRNP K and Sam68. hnRNP K has been shown to bind pre-mRNA splicing enhancers and silencers, with direct phosphorylation of hnRNP K by Src-kinases, Protein Kinase C (PKC), ERK1/2, and JNK altering proteinprotein and protein-RNA binding patterns of this splicing factor (Bomsztyk et al. 2004). Similarly, Sam68 binds elements within pre-mRNA and can become phosphorylated by kinases such as ERK (Matter et al. 2002). An excellent review of these splicing hubs can be found in (Lynch 2007).

Splicing hubs such as Sam68 and hnRNP K are involved in cancer pathology in several ways. First, their expression 
levels are often altered. For example, immunostaining of colorectal cancer tissue reveals a significant association between cytoplasmic hnRNP K expression and stage of disease (Hope and Murray 2011). Also, melanoma cell lines and tissues express higher levels of hnRNP K compared to normal melanocytes and benign nevi, respectively (Wen et al. 2010).

Second, aberrant upstream signals typical in cancer can alter normal post-translational modifications and thus localization and activity of splicing factors. Both hnRNP K (Lewis et al. 2000) and Sam68 (Matter et al. 2002) are targets for phosphorylation by ERK - a component of the Ras/MAPK signaling pathway that is frequently hyperactive in cancer due to $B R A F$ mutation. For example, in melanoma, enhanced Ras/MAPK signaling through MEK increases the ratio of microphthalmia-associated transcription factor (MITF) MITF(-) to MITF(+) spliced isoforms (Primot et al. 2010). Although implicated as an oncogene in transformed melanocytes, MITF normally regulates melanocyte development (Levy et al. 2006). Citing the pro-proliferative activity of the MITF(-) isoform (Blaustein et al. 2005), Galibert and colleagues propose that up-regulation of MEK in melanoma resulting in altered MITF splicing is a mechanism by which tumor cells achieve enhanced proliferation (Primot et al. 2010). The phosphatase and tensin homolog (PTEN) and Akt pathway is another growth factor signaling cascade frequently mutated in many cancers. Akt is activated by phosphoinositide-3-kinase (PI3K), and phosphorylates several distinct SR proteins such as SRp40 (Patel et al. 2005) and SF2/ASF (White et al. 2010) that ultimately regulate splicing events. For example, aberrant Akt signaling affects splicing of Casp9 in non-small cell lung cancers (Shultz et al. 2010).

Third, alterations in expression and activity of splicing factors hnRNP K and Sam68 can disrupt normal splicing patterns of their targets. For Sam68, such targets have been extensively reviewed and include CD44 involved in cell migration, invasion, and proliferation; Cyclin D1 involved in regulation of the cell cycle; and BCL-X involved in apoptosis (reviewed in Bielli et al. 2011).

\section{Microenvironments affecting translation}

Among the groups of proteins that are translationally upregulated in cancer, growth factors stand out because of their role in proliferation and cancer progression. A deeply integrated growth factor response involving, but not limited to, FGF, Wnt, and $\beta$-catenin involves translation (Créancier et al. 2000; Nathan et al. 1997; Pond et al. 2010). Signaling through FGFR results in the phosphorylation of key mediators of the translational response like ribosomal S6. This causes an increase in the recruitment of Wnt, $\beta$-catenin, and eIF transcripts to polysomes (Nathan et al. 1997). Phenotypically there is a rapid increase in palpable tumors in response to FGFR signaling in mice injected with breast cancer cell lines (Nathan et al. 1997).

Several studies have suggested that changes in the translation of FGF contribute to tumorigenicity (Folkman and Hanahan 1991; Vagner et al. 1995). FGF2 can be translated by either IRES or cap-dependant translation. These methods dictate the start site used for translation resulting in different isoforms of FGF2. Normally FGF isoforms show tissue specificity and are required for normal neural development (Créancier et al. 2000; Wagner 1991). The IRES derived isoforms are expressed in transformed cells and under conditions of stress. Given the known role of FGF in cancer, it is not surprising that FGF2 isoforms exhibit tumorigenic phenotypes causing neovascularization of tumor and immortalization of NIH-3T3 cells (Folkman and Hanahan 1991; Vagner et al. 1995). It is becoming clear that perturbations in communication between the FGF pathway and translation contribute to the progression of many tumors (Nathan et al. 1997). FGF is just one example of the interconnectedness of growth factors and translational signaling. Other translationally controlled proteins like ER $\alpha$, VEGF, platelet-derived growth factor (PDGF), FGF2, IGF-1 receptor, and TGF- $\beta 1$ might show similar levels of regulatory complexity (Fraser et al. 2002; Stoneley and Willis 2004).

External stimuli including growth factors, hormones, cytokines, extracellular matrix components, and mitogens activate the PI3K/Akt pathway and affect translation through mTOR (Chung et al. 2002; Hay and Sonenberg 2004; Hennessy et al. 2005; Kroczynska et al. 2009; Petroulakis et al. 2007; Remy et al. 2004; Stephens et al. 2005). Indeed, several studies show that mTOR regulated by Akt mediates transformation through multiple mechanisms including translational repression (Aoki et al. 2001; Sodhi et al. 2006) Importantly, the RAS/MAPK and PI3K/AKT pathways that both regulate mTOR and translation are among the most frequently altered pathways in cancer. mTOR activity is also regulated by oxygen deprivation and nutrient levels (Holcik and Sonenberg 2005). Convergence of these signals results in an extensive and integrated mechanism that enables cells to respond to the microenvironment.

Hypoxia in the microenvironment

Perhaps one of the most pervasive microenvironmental factors affecting cell phenotype is $\mathrm{O}_{2}$ availability. Hypoxia occurs when oxygen supply to a tissue is deficient. A state of hypoxia is normal in some contexts such as early embryonic development, but also arises in regions of tumors where vascular networks delivering oxygen have failed to penetrate.

Hypoxia promotes the stabilization of hypoxia inducible factor $\alpha$ (HIF- $\alpha)$ proteins, the best studied of which is HIF$1 \alpha$, which dimerizes with HIF- $1 \beta$ and translocates to the 
nucleus to regulate transcription. Cytoplasmic levels of HIF$1 \beta$ are stable under hypoxic and normoxic conditions. HIF$1 \alpha$ protein levels rapidly increase in response to low oxygen resulting from protein stabilization by inactivation of prolylhydroxylase which normally targets HIF- $1 \alpha$ for degradation (reviewed in Semenza 2003). Following stabilization, nuclear translocation occurs. In the nucleus, HIF-1 acts as a transcription factor increasing the expression of genes that have hypoxia-response elements (HREs) in their promoter region. HIF-1 activity is associated with genes regulating cell motility and invasion such as fibronectin and matrix metalloproteinase (MMP)-2, ECM-modifying enzymes such as lysyl oxidase (LOX), as well as pluripotency factors including OCT4, NANOG, and SOX2 (Erler et al. 2006; Forristal et al. 2010; Semenza 2003). The hypoxic microenvironment has been implicated in promoting cellular transformation, as well as subsequent tumor development, invasion, and metastatic spread (e.g. Bedogni and Powell 2009).

\section{Splicing response to hypoxia}

A few groups have investigated global patterns of AS in response to hypoxia using exon array technology. Using normal human umbilical vein endothelial cells, Zhang and colleagues found 342 exons that displayed differential inclusion in processed transcripts when cells were treated with cobalt chloride to mimic hypoxic stress (Hang et al. 2009). Hypoxic down-regulation of splicing factors heteronuclear ribonucleoprotein (hnRNP) H1 and arginine/serine-rich (SR) 5 in mouse fibroblasts offers mechanistic support to the notion that hypoxia alters global patterns of AS (Greijer et al. 2005).

Hypoxia-associated splicing is also relevant in cancer. A screen of Head and Neck Squamous Cell Carcinoma (HNSCC) samples with either low or high "Hypoxia Scores" (Winter et al. 2007) found several transcripts demonstrating a correlation between Hypoxia Score and the ratio of alternatively spliced transcript isoforms (Moller-Levet et al. 2009). Specifically, this study identified preferred splicing in hypoxia of Laminin $\alpha 3$ (LAMA3) isoform LAMA3A, over full length LAMA3-B. While LAMA3 is known to be involved in tumor cell invasion, HNSCC patients in the highest quartile for expression of the LAMA3-A isoform demonstrated decreased survival compared to those with expression in the lower three quartiles. Importantly, this correlation was not seen in patients who expressed the highest relative levels of LAMA3-B. This suggests LAMA3-A is an isoform-specific hypoxia induced prognostic biomarker for disease progression. In breast cancer, AS of CCN1 (Cyr61) is influenced by hypoxia (Hirschfeld et al. 2009). Using RT-PCR and immunocytochemistry, Hirschfeld and colleagues demonstrated that hypoxia promotes a shift in CCN1 splicing toward the aforementioned intron 3-skipping isoform capable of generating full length functional protein.
Cell lines cultured in hypoxia demonstrated increased splicing of the intron-skipping isoform, and stronger cytosolic expression of the corresponding protein. These changes were consistent with increased splicing of the intronskipping isoform in tumor versus matched normal samples, and increased protein expression in invasive ductal carcinoma cells compared to adjacent non-neoplastic ductal epithelium, with the former presumably representing more hypoxic tissue (Hirschfeld et al. 2009). In neuroblastoma, hypoxic stress mimicked by cobalt chloride influenced the AS of a tumor-suppressing neurotrophin tyrosine kinase receptor (TrkA). Hypoxic stress increased splicing of the TrkAIII isoform normally restricted to neural progenitor cells that was shown to antagonize normal TrkA signaling, thus promoting tumor progression through increased tumor angiogenesis (Tacconelli et al. 2004). From these examples, it is clear that the hypoxic microenvironment can induce splicing of transcript isoforms that promote tumor progression.

Translational response to hypoxia

As the master transcriptional regulator of the hypoxic response, HIF-1 capitalizes on the change from cap-dependant to cap-independent translation in order to accumulate in response to low levels of oxygen (Rofstad et al. 2002). An often overlooked aspect of HIF- $1 \alpha$ regulation is translation. In order to sustain the high nuclear levels of HIF- $1 \alpha$ required for an hypoxic response, mRNA must continue to be translated. It is well established that HIF- $1 \alpha$ contains an IRES that allows for efficient translation during oxygen deprivation and serum starvation (Görlach et al. 2000; Lang et al. 2002). The intranuclear accumulation of HIF-1 requires two types of posttranscriptional regulation: Translation via the IRES and an increase in protein stability act in concert to coordinate extensive changes in protein expression.

HIF- $1 \alpha$ translation can also be affected by tumor promoting driver mutations for example the oncogenic PML deletion as well as KRAS and BRAF mutations increase the translation of HIF- $1 \alpha$ in response to hypoxia (Bernardi et al. 2006; Kikuchi et al. 2009). These studies elegantly demonstrate the combinatorial regulation of tumor progression and suggest how mutation, microenvironmental factors and translational mechanics can have cumulative effects in cancer.

There are many other genes that are up-regulated translationally that contribute to cancer progression. The number of known genes that have IRES sequences is growing rapidly and includes key modulators of pluripotency (OCT4) (Wang et al. 2009) and tumor progression (VEGF) (Huez et al. 1998). Understanding the biological relevance of translating these genes in a cap-independent manner still requires a lot of work, but it offers new and interesting ways of viewing the progression of cancer. Several genes, including SOX2, c-myc, mdm2, uPAR, XIAP, and VEGF have been 
shown to be translationally regulated and are important in disease progression (Chung et al. 2002; Ge et al. 2010; Genolet et al. 2011; Graff et al. 2007; Riley et al. 2010; Tan et al. 2000). For example, SOX2 and OCT4 have been identified as being associated with subpopulations of cells with enhanced tumorigenic properties (Ge et al. 2010; Wang et al. 2009). Of the CCN proteins, CCN1 has been shown to be regulated by hypoxia and an IRES (Johannes et al. 1999; Mukudai et al. 2010). Kunz et al. identified CCN1 as a hypoxia-induced gene in melanoma. The absolute expression of CCN1 also correlated with cancer aggressiveness suggesting the expression is being selected for as melanoma becomes more severe (Kunz et al. 2003). Mechanistically, gene expression analysis determined that $\mathrm{CCN} 1$ was upregulated by HIF- $1 \alpha$ and AP-1. Like many other hypoxia regulated proteins, $\mathrm{CCN} 1$ has been shown to be capable of cap-independent translation. The over-expression of EIF4F, as is common in many cancers, increases the association of CCN1 mRNA with polysomes (Johannes et al. 1999; Nasr et al. 2012). Under conditions of hypoxia, CCN1 also activates important signalling pathways including MAPK, PI3K, as well as NF-KB, resulting in the up-regulation HIF- $1 \alpha$ of in gastric cancer (Lin et al. 2008). Interestingly, this upregulation was shown to be the result of de novo protein synthesis, rather than through stabilization of HIF- $1 \alpha$ as is typically observed. CCN1 affects numerous phenotypes like proliferation, migration and vascularization and offers a compelling mechanism explaining signal integration among the ECM and growth factors (Kunz et al. 2003; Lin et al. 2008). Factors like these are in part responsible for invasive and metastatic cancer phenotypes.

Recently, a study has demonstrated that key protumorigenic proteins are able to evade the hypoxia-induced repression of cap-dependent translation (Uniacke et al. 2012). In this study, it was discovered that hypoxia stimulates the formation of a complex consisting of HIF- $2 \alpha$, the cap binding protein EIF4E2 and an RNA binding protein (RBM4). This complex is recruited to RNA Hypoxia Responsive Elements (rHREs) in a manner that captures the $5^{\prime}$ cap and targets the mRNA for translation. It is not known if this process is utilized to promote the translation of genes such as OCT4 and VEGF; however, it has been shown to regulate pro-mitogenic receptors such as Epidermal Growth Factor Receptor (EGFR) and Platelet Derived Growth Factor Receptor A (PDGFRA).

\section{Regulation of alternative splicing and translation in the progression of cancer}

\section{Angiogenesis and VEGF splicing}

Angiogenesis is the formation of new blood vessels and is recognized as one of the "hallmarks of cancer" (Hanahan and Weinberg 2000, 2011) since a rapidly growing tumor necessitates generation of a vascular network to keep tumor tissue supplied with oxygen and nutrients for growth and metabolism. No factor is more integral to the subsistence of tumor angiogenesis than VEGF. Although normally repressed in most adult tissues, VEGF becomes increasingly expressed and promotes an "angiogenic switch" for sustained tumorigenesis in cancers such as melanoma (Ria et al. 2010). Interestingly, AS yields multiple isoforms of VEGF, including a subset of transcripts that actually demonstrate antiangiogenic activity referred to as $\mathrm{VEGF}_{\mathrm{xxxb}}$ (reviewed in Ladomery et al. 2007), where $\mathrm{xxx}$ denotes the number of amino acids of a particular isoform (Ferrara 1999). The VEGF $_{165 \mathrm{~b}}$ isoform prevents normal angiogenesis in response to hypoxia and proliferation in response to VEGF in vitro, and also plays an anti-angiogenic role in vivo. Injection of nude mice with various cancer cell lines over-expressing $\mathrm{VEGF}_{165 \mathrm{~b}}$ resulted in smaller tumors relative to those in mice injected with VEGF ${ }_{165}$ over-expressing cells. This has been demonstrated for the A375 (Woolard et al. 2004) and Mel57 (Rennel et al. 2008) melanoma cell lines. However, the anti-angiogenic activity of some $\mathrm{VEGF}_{\mathrm{xxxb}}$ isoforms has recently been disputed. It has been suggested that $\mathrm{VEGF}_{121 \mathrm{~b}}$ and $\mathrm{VEGF}_{165 \mathrm{~b}}$ are in fact weakly angiogenic and are up-regulated in some breast cancers relative to normal tissue (Catena et al. 2010). Therefore, there are likely other mechanisms that modulate the angiogenic activity of $\mathrm{VEGF}_{\mathrm{xxxb}}$ isoforms.

The VEGF $_{\mathrm{xxxb}}$ transcripts are the predominant class of isoforms in most normal adult tissues such as renal cortex (Bevan et al. 2008). However, many cancers express the majority of VEGF in the $\mathrm{VEGF}_{\mathrm{xxx}}$ form. As examples, $\mathrm{VEGF}_{\mathrm{xxxb}}$ isoforms are endogenously down-regulated in renal cancer compared to normal tissue (Bates et al. 2002), and in metastatic relative to benign prostate tumors (Woolard et al. 2004). In human melanoma, Bates and colleagues used PCR and immunohistochemistry to demonstrate that patients who subsequently developed metastatic disease (within 8 years after samples were taken) displayed higher pan-VEGF to $\mathrm{VEGF}_{\mathrm{xxxb}}$ ratios during both radial growth phase and vertical growth phase, due to reduced levels of $\mathrm{VEGF}_{\mathrm{xxxb}}$ isoforms, relative to patients with tumors that did not later metastasize (Pritchard-Jones et al. 2007). These findings suggest that as disease progresses, tumors actively switch splicing in favor of the angiogenic $\mathrm{VEGF}_{\mathrm{xxx}}$ isoforms, contributing to sustained angiogenesis and tumor progression.

The $\mathrm{VEGF}_{\mathrm{xxxb}}$ isoforms differ from their $\mathrm{VEGF}_{\mathrm{xxx}}$ counterparts due only to selection of a more distal splice site in the eighth and most $3^{\prime}$ exon. This splice site choice results in six $\mathrm{C}$-terminal amino acids that are divergent in sequence between these two classes of VEGF isoforms and accounts for their drastically opposing functions (Ladomery et al. 2007).

Microenvironmental factors have been shown to promote expression of VEGF. Hypoxia (Liao and Johnson 2007) and 
growth factors including TGF- $\beta$ are obvious candidates to regulate VEGF splicing. However, prior to 2008, only a few factors had been explored in terms of their ability to regulate splicing of VEGF, and no factors had been shown to specifically influence splicing of $\mathrm{VEGF}_{\mathrm{xxxb}}$ transcript isoforms (reviewed in Ladomery et al. 2007). Since then, Bates and colleagues have investigated the impact of TNF- $\alpha$, IGF, and TGF- $\beta 1$ signaling on the VEGF/VEGF ${ }_{\mathrm{xxxb}}$ splice decision (Nowak et al. 2008). Treatment of two different epithelial cell types with either IGF or TNF- $\alpha$ resulted in increased expression of total VEGF protein and concomitant decreased expression of the $\mathrm{VEGF}_{\mathrm{xxxb}}$ protein isoforms. Specifically, IGF was able to induce a complete splice switch of VEGF in retinal pigmented epithelial cells, from $80 \%$ to a mere $5 \%$ of VEGF spliced as $\mathrm{VEGF}_{\mathrm{xxxb}}$. Subsequent work demonstrated that IGF-induced splicing of VEGF acts through PKC and SRPK1 (Nowak et al. 2010). Conversely, although TGF- $\beta 1$ also increased total VEGF expression, this growth factor skewed splicing toward the anti-angiogenic $\mathrm{VEGF}_{\mathrm{xxxb}}$ isoforms. This change in splicing was shown to be mediated by $\mathrm{p} 38$ MAPK signaling (Nowak et al. 2008). The splicing of VEGF is a wellstudied example of how the tumor microenvironment can actively perturb AS to favor isoforms that enhance tumor progression. Although VEGF is a major player in the process of angiogenesis, it is likely that changes in the AS of other angiogenic factors likely act in concert with VEGF to collectively promote sustained tumor angiogenesis (Harper and Bates 2008; Ladomery et al. 2007; Nowak et al. 2008; Pritchard-Jones et al. 2007).

\section{Translation of VEGF isoforms in tumor angiogenesis}

Despite having a known role in growth and maintenance of multiple tumors, the full regulatory mechanism governing VEGF function has yet to be characterized. Oxygen concentration appears to be one of the most potent regulators of VEGF expression (Stein et al. 1998). The presence of two IRESs in the $5^{\prime}$ UTR helps to maintain translation during environmental insult such as hypoxia or other stress conditions and supports VEGF expression (Abcouwer et al. 2002; Stein et al. 1998). The expression of VEGF in response to the microenvironment requires the transduction of multiple signaling pathways that can upregulate translation.

Consistent with the translational regulation of other proteins, the rate of translation of VEGF is affected by PI3K/ AKT signaling (Chung et al. 2002; DeFatta et al. 2000; Kevil et al. 1996). For example, the presence of $\alpha 6 \beta 4$ integrins was demonstrated to induce VEGF expression via the PI3K/AKT pathway (Chung et al. 2002). In this study, the $\alpha 6 \beta 4$-mediated increase in VEGF protein occurred without a concomitant up-regulation of VEGF mRNA. Rather, translation was increased as a result of the cytoplasmic domain of the $\beta$-integrin signaling acting through AKT to decrease the phosphorylation of 4E-BP. It is clear that VEGF regulation is the sum of a number of signals, several of which regulate VEGF at the level of translation (Chung et al. 2002).

From the single VEGF gene, a multitude of alternatively spliced proteins and two alternatively translated isoforms can be produced (Houck et al. 1991; Huez et al. 1998, 2001; Lei et al. 1998; Leung et al. 1989; Poltorak et al. 1997; Tischer et al. 1991). Selection of the upstream start site that dictates the translated isoform is controlled by an IRES. The resulting additional 180 amino acid sequence is highly conserved among mammals suggesting a conserved function (Bornes et al. 2004). Using three expression splice variants with a mutation to prevent further processing and an HA tag for identification, Bornes et al. found that the splice variants showed distinct preferences in start site selection. VEGF $_{189}$ primarily utilized the canonical start codon. VEGF $_{121}$ was expressed exclusively from the upstream codon and $\mathrm{VEGF}_{165}$ was expressed equally from both codons (Bornes et al. 2004). Surprisingly, hypoxia had no effect on the pattern of expression of VEGF translational isoforms. It is still unclear what factors regulate this process and what role this extensive regulation plays in cancer. What is becoming clear is that the mechanisms of splicing and translation act cooperatively to determine both expression and protein sequence.

\section{Regulation of epithelial-mesenchymal transition (EMT) in cancer}

The epithelial to mesenchymal transition (EMT) is a process fundamental to embryonic development that is sometimes aberrantly induced within tumors. This process involves the loss of epithelial E-cadherin and gained expression of $\mathrm{N}$ cadherin and vimentin, allowing migratory and invasive abilities that ultimately potentiate metastatic spread (Thiery et al. 2009). Along with widespread changes in gene expression, reprogramming of AS (Shapiro et al. 2011; Thiery et al. 2009) and translation coincide with EMT.

\section{Role of alternative splicing in the regulation of EMT}

In the tumor microenvironment, basic fibroblast growth factor (bFGF) is an important protein secreted by stromal cells (Villanueva and Herlyn 2008), to which tumor cells are responsive due to expression of receptor tyrosine kinase FGF receptors. FGFR2 is one of these receptors and is subjected to AS. The mutually exclusive exons IIIb and IIIc are included in processed transcripts in normal epithelial and mesenchymal cells, respectively (Yan et al. 1993). Moreover, this transcript undergoes a drastic switch in splicing from including exon IIIb to including exon IIIc during 
EMT, with inclusion of exonIIIc associated with reduced affinity of the ligand-binding domain of FGFR2 for FGF7 (Yan et al. 1993). It has also been suggested that both EMT and mesenchymal to epithelial transition (MET) occur within a prostate tumor model, with FGFR2 splicing modulating this potential for bidirectional phenotypic plasticity that enhances malignancy (Oltean et al. 2006).

Ron is a receptor tyrosine kinase for macrophagestimulating protein that plays a role in cellular invasion through extracellular matrices, an important process in early development that again becomes exploited by some tumor cells during EMT. One of the alternatively spliced Ron isoforms ( $\Delta$ Ron) lacks exon 11 and translates a constitutively active oncogenic isoform of Ron (Collesi et al. 1996). In both T47D and 293 cells that normally include exon 11 in the majority of Ron transcripts, SF2/ASF over-expression induced increased skipping of exon 11, dependent on an exon splicing enhancer element within constitutive exon 12 (Ghigna et al. 2005). SF2/ASF over-expression in cl.SF2 cells promoted decreased expression of the epithelial marker E-cadherin as assessed by immunofluorescence and RTPCR, the acquisition of an elongated spindle-shaped morphology, and increased motility in a transwell migration assay-phenotypes common to $\Delta$ Ron over-expression and resulting constitutive Ron signaling (Bardella et al. 2004; Collesi et al. 1996; Wang et al. 2004). These data suggest that there is likely a role for SF2/ASF in altering Ron splicing to enhance EMT.

Mena interacts with members of actin remodeling networks important for cytoskeletal changes essential for cell migration. Several cancers express increased levels of Mena (Di Modugno et al. 2004). In breast cancer, Mena expression is positively correlated with an increased capacity of tumor cells for invasion (Di Modugno et al. 2006). Different patterns of AS exist for Mena due to four alternatively included exons. Specifically, the "Mena ${ }^{\mathrm{INV}}$ " (Philippar et al. 2008) isoform containing the "+++" exon but lacking the "11a" exon is associated with invasive potential (Goswami et al. 2009). Stable MTLn3 cell lines expressing EGFPtagged Mena ${ }^{\mathrm{INV}}$ and injected into SCID mice produced orthotopic breast tumors with significantly more motile cells, and significantly more lung metastases compared to mice injected with cells expressing either EFGP or EGFPMena (Philippar et al. 2008). Mechanistically, Mena ${ }^{\mathrm{INV}}$ was shown to contribute to increased invasion and metastasis through regulation of epidermal growth factor signaling and stabilization of invadopodia (Philippar et al. 2008).

Although the functional impact of splice switching events for transcripts such as FGFR2 during EMT remain to be detailed, the regulation of these splicing events has been the focus of comprehensive reviews (David and Manley 2010; Luco et al. 2011). As examples of the above mentioned factors involved in EMT, FGF receptor splicing is regulated by TGF- $\beta$ signaling (Shirakihara et al. 2011), while the ERK1/2 target Sam68 affects levels of SF2/ASF involved in EMT and MET splicing regulation as illustrated above in the case of Ron (Valacca et al. 2010). In this vein, it seems likely that an EMT "splicing signature" exists, analogous to the "invasion signature" defined by coordinated transcriptional changes during invasion (Philippar et al. 2008; Wang et al. 2004, 2007). In support of this notion, splicing of FGFR2, Mena, CD44, p120-catenin, and EPB41L5 (all important in EMT) is regulated by the two RNA binding proteins epithelial splicing regulatory proteins 1 and 2 (ESRP1 and ESRP2) (Warzecha et al. 2009a, b). An "oncogenic splicing switch" driven by hnRNP $\mathrm{H}$ has also been proposed in glioma, promoting splicing of the anti-apoptotic IG20 isoform MADD, and constitutively active Ron (Lefave et al. 2011). Most recently, transcriptome-wide analysis of splicing changes in a Twist-induced model of EMT revealed hundreds of genes with altered splicing patterns, many of which are regulated by three splicing factors ESRP1, RBFOX2, and PTB. Furthermore, a set of nine of these splicing events with validated and robust changes during EMT had predictive value in classifying breast cancer cell lines as either luminal (generally poorly metastatic) or basal (generally more aggressive and metastatic) (Shapiro et al. 2011). The existence of splicing signatures for other processes integral to tumor progression such as angiogenesis has also been hypothesized (Harper and Bates 2008; Ladomery et al. 2007; Nowak et al. 2008; Pritchard-Jones et al. 2007). While this concept might also extend to an overall malignant signature, much remains to be discovered in both regards.

\section{Regulation of translation in EMT}

Translation has been shown to control the expression of an important regulator of EMT, Snail. Increased levels of Snail and Y-box factor-1 (YB-1) have been shown in invasive breast epithelial cells (Evdokimova et al. 2009). YB-1 promotes the expression of Snail, N-cadherin, and TWIST. Snail expression is maintained in breast epithelial cells treated with mTOR inhibitors, suggesting that it may be translated via cap-independent mechanisms. Indeed, luciferase activity detected from a Snail-5'UTR-luciferase reporter suggests that its translation is maintained during mTOR inhibition (Evdokimova et al. 2009). Mechanistically it was determined that YB-1, when phosphorylated by AKT, is a repressor of cap-dependent translation which allows for the up-regulation of IRES-containing mRNAs including Snail (Evdokimova et al. 2006). Furthermore, other studies have shown that HIF-1 $\alpha$ and Snail may be translationally regulated simultaneously to support the down-regulation of E-cadherin associated with EMT (Imai et al. 2003). These data suggest that EMT is, in part, regulated by hypoxia and YB-1 through IRES-dependent regulation of Snail. 
Some of the most prominent communication between splicing and translation has been described in the context of EMT. The translation of zinc finger E-box binding homeobox 2 (ZEB2) mRNA during EMT is regulated by a novel mechanism in human colorectal cancer. In one study, EMT was induced by transfection of Snail (Beltran et al. 2008). The amount of ZEB2 protein was increased during EMT without the expected transcriptional activation of the gene. It was determined that a previously discovered natural antisense transcript (NAT) binds to the 5'UTR of the ZEB2 transcript, preventing splicing and leading to the retention of the IRES. The regulation of ZEB2 offers a new and exciting model of regulation for EMT wherein translation and splicing work in combination.

Recent data suggest that splicing and translation may coactivate the same pathways to promote similar phenotypes. hnRNP E1 is a translational regulator as well as a regulator of splicing. In a review by Chaudhury et al., the multiple roles of hnRNP E1 as a translational regulator and as a splicing factor are well summarized (Chaudhury et al. 2010a). hnRNP is integral in TGF- $\beta$-mediated EMT. Using a number of models including oncogenic RAS- transformed mouse mammary epithelial cells, Howe and colleagues showed that TGF- $\beta$ upregulates translation of Dab2 and ILEI, contributing to EMT (Chaudhury et al. $2010 b)$. Both Dab2 and ILEI contained TGF- $\beta$-activated translation (BAT) elements in their 3'UTR. BAT elements are bound by the BAT-binding messenger ribonucleoprotein (mRNP) complex that silences translation. One component of this complex, hnRNP E1, is phosphorylated in response to TGF- $\beta$ signaling via AKT2 activity, disrupting binding of Dab2 and ILEI and increasing the efficiency of translation. Though the full extent of interaction between splicing and translation has yet to be discovered, research to date indicates convergent effects on phenotype, co-operative regulation of single genes and even shared components of the machinery required for both types of regulation.

\section{Conclusion}

Cancer is characterized by cellular adaptation to changing microenvironments and by hallmarks such as angiogenesis and EMT. These critical processes are mediated by the

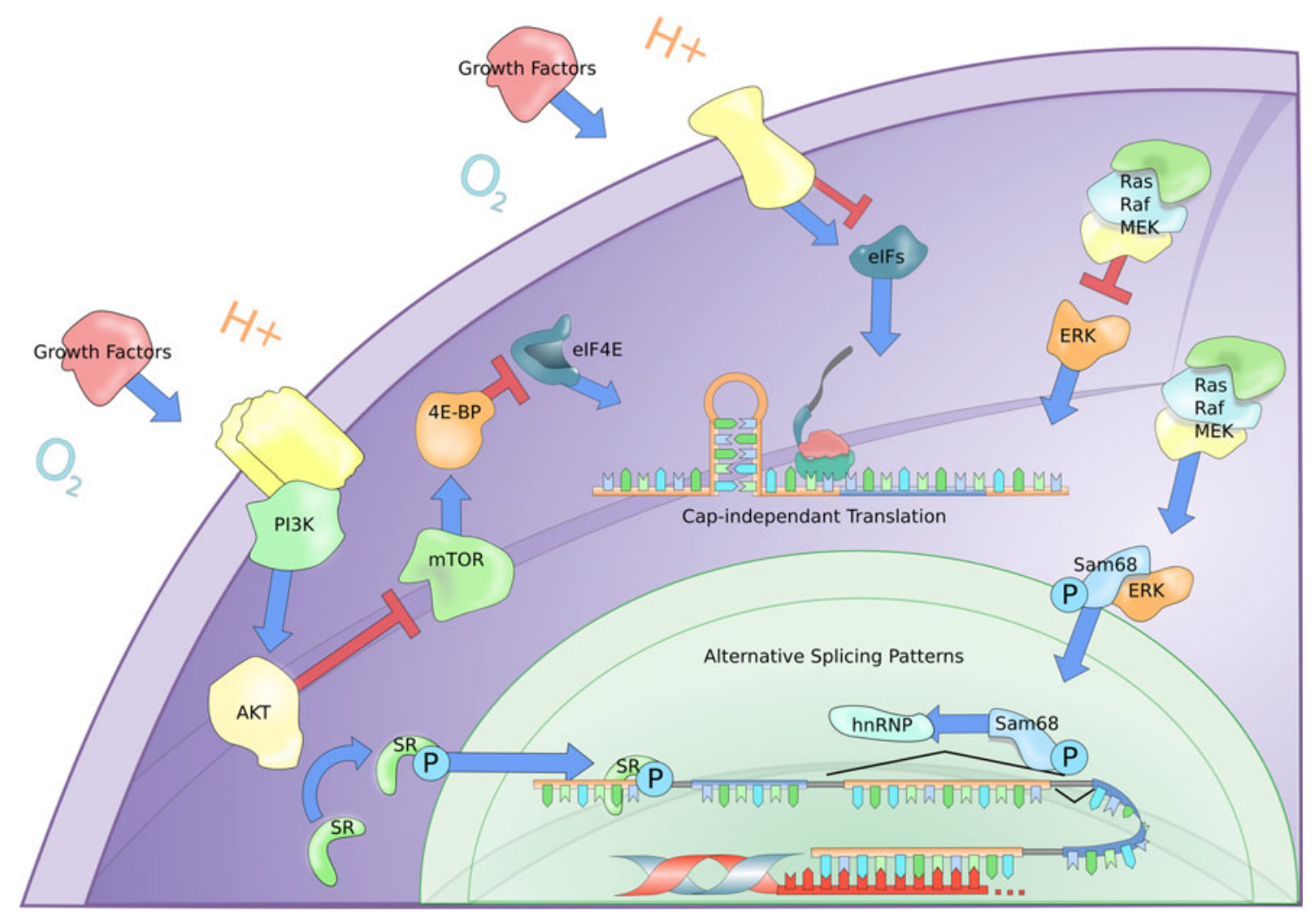

Fig. 3 A summary of how microenvironmental factors typically affect signaling pathways regulating alternative splicing and translation. Blue arrows indicate activating effects, although not necessarily an active protein, and red bars indicate inhibiting effects. Extracellular activation of PI3K causes an activation of AKT resulting in the phosphorylation of SR proteins and mTOR, directly altering splicing patterns and the dynamics of translation, respectively. Inhibition of mTOR enhances cap-independent translation through derepression of 4EBP causing inactivation of eIF4E. The RAS/MEK pathway is also involved in promoting cap-independent translation through other eIF proteins. Components of both of these pathways (AKT and ERK), also phosphorylate SR proteins, altering their RNA binding specificities and thus patterns of splicing 
increased transcription of a myriad of genes, including VEGF, FGFR, and Snail. In addition to these classical changes in gene expression, it is clear that alterations in the splicing and translation of these genes also contribute to rapid expression of pro-tumorigenic proteins. Furthermore, changes in transcription, splicing, and translation do not take place in isolation, as there is much evidence for coordinated regulation of these processes. First, AS actually takes place cotranscriptionally. According to the kinetic model, a slower rate of transcription allows inclusion of weak alternative exons, while the recruitment model posits that specific splicing factors can bind RNA polymerase II to increase their local concentration at target splice sites and thereby strengthen the interaction (Kornblihtt 2007; Luco et al. 2011). Second, enzymes that modify histones to modulate the accessibility of specific genetic loci to the transcriptional machinery can also modulate AS events through binding small nuclear ribonucleoproteins components of the spliceosome (reviewed in Luco et al. 2011). For example, EMT-associated decreases in FGFR2 histone 3 lysine 27 trimethylation (H3K27me3) and $\mathrm{H} 3 \mathrm{~K} 4 \mathrm{me} 3$, and increases in H3K36me 3 and $\mathrm{H} 3 \mathrm{~K} 4 \mathrm{me} 1$ was shown to causally promote the corresponding FGFR2 splice switch discussed above (Luco et al. 2010).

Along with several other aspects of mRNA metabolism, splicing and translation are both regulated by the SR proteins (Huang and Steitz 2005). Srebrow and colleagues used the fibronectin gene to illustrate that the PI3K/AKT pathway can influence SR protein activity and thus regulate both AS and translation in an isoform-specific fashion (Blaustein et al. 2005). The splicing factor SF2/ASF also recruits mTOR to some transcripts (Michlewski et al. 2008), while hnRNP K is involved in regulation of translation as previously illustrated. Collectively, these examples emphasize the widespread perturbation of post-transcriptional regulation in cancer.

Thus, we propose an integrated model for changes in gene expression during cancer progression (Fig. 3). That is, tumor cells respond to and forge their microenvironment via modulation of gene expression through not only classical transcriptional responses, but also inter-dependent posttranscriptional processes including AS and translation. These changes favor tumor cell plasticity, enabling protumorigenic processes affording cellular growth and metastasis. Future work that considers post-transcriptional levels of regulation will do much to identify novel genes and mechanisms that contribute to tumor progression.

\section{References}

Abcouwer SF, Marjon PL, Loper RK, Vander Jagt DL (2002) Response of VEGF expression to amino acid deprivation and inducers of endoplasmic reticulum stress. Invest Ophthalmol Vis Sci 43:2791-2798
Aoki M, Blazek E, Vogt PK (2001) A role of the kinase mTOR in cellular transformation induced by the oncoproteins P3k and Akt. Proc Natl Acad Sci U S A 98:136-141

Avdulov S, Li S, Michalek V, Burrichter D, Peterson M, Perlman DM, Manivel JC, Sonenberg N, Yee D, Bitterman PB et al (2004) Activation of translation complex eIF4F is essential for the genesis and maintenance of the malignant phenotype in human mammary epithelial cells. Cancer Cell 5:553-563

Babic AM, Kireeva ML, Kolesnikova TV, Lau LF (1998) CYR61, a product of a growth factor-inducible immediate early gene, promotes angiogenesis and tumor growth. Proc Natl Acad Sci U S A 95:6355-6360

Bardella C, Costa B, Maggiora P, Patane' S, Olivero M, Ranzani GN, De Bortoli M, Comoglio PM, Di Renzo MF (2004) Truncated RON tyrosine kinase drives tumor cell progression and abrogates cell-cell adhesion through E-cadherin transcriptional repression. Cancer Res 64:5154-5161

Bates DO, Cui T-G, Doughty JM, Winkler M, Sugiono M, Shields JD, Peat D, Gillatt D, Harper SJ (2002) VEGF165b, an inhibitory splice variant of vascular endothelial growth factor, is downregulated in renal cell carcinoma. Cancer Res 62:4123-4131

Bedogni B, Powell MB (2009) Hypoxia, melanocytes and melanoma survival and tumor development in the permissive microenvironment of the skin. Pigment Cell Melanoma Res 22:166-174

Bellavia D, Mecarozzi M, Campese AF, Grazioli P, Gulino A, Screpanti I (2007) Notch and Ikaros: not only converging players in T cell leukemia. Cell cycle 6:2730-2734

Beltran M, Puig I, Peña C, García JM, Alvarez AB, Peña R, Bonilla F, de Herreros AG (2008) A natural antisense transcript regulates Zeb2/Sip1 gene expression during Snail1-induced epithelialmesenchymal transition. Genes Dev 22:756-769

Bernardi R, Guernah I, Jin D, Grisendi S, Alimonti A, TeruyaFeldstein J, Cordon-Cardo C, Simon MC, Rafii S, Pandolfi PP (2006) PML inhibits HIF-1alpha translation and neoangiogenesis through repression of mTOR. Nature 442:779-785

Bevan HS, van den Akker NMS, Qiu Y, Polman JAE, Foster RR, Yem J, Nishikawa A, Satchell SC, Harper SJ, Gittenberger-de Groot AC et al (2008) The alternatively spliced anti-angiogenic family of VEGF isoforms VEGFxxxb in human kidney development. Nephron Physiol 110:57-67

Bielli P, Busa R, Paronetto MP, Sette C (2011) The RNA-binding protein Sam68 is a multifunctional player in human cancer. Endocr Relat Cancer 18:91-102

Blaustein M, Pelisch F, Tanos T, Muñoz MJ, Wengier D, Quadrana L, Sanford JR, Muschietti JP, Kornblihtt AR, Cáceres JF et al (2005) Concerted regulation of nuclear and cytoplasmic activities of SR proteins by AKT. Nat Struct Mol Biol 12:1037-1044

Bomsztyk K, Denisenko O, Ostrowski J (2004) hnRNP K: one protein multiple processes. Bioessays 26:629-638

Bornes S, Boulard M, Hieblot C, Zanibellato C, Iacovoni JS, Prats H, Touriol C (2004) Control of the vascular endothelial growth factor internal ribosome entry site (IRES) activity and translation initiation by alternatively spliced coding sequences. J Biol Chem 279:18717-18726

Catena R, Larzabal L, Larrayoz M, Molina E, Hermida J, Agorreta J, Montes R, Pio R, Montuenga LM, Calvo A (2010) VEGF $_{121} \mathrm{~b}$ and VEGF $_{165}$ b are weakly angiogenic isoforms of VEGF-A. Mol Cancer 9:320

Chang M-L, Chen J-C, Alonso CR, Kornblihtt AR, Bissell DM (2004) Regulation of fibronectin splicing in sinusoidal endothelial cells from normal or injured liver. Proc Natl Acad Sci USA 101:1809318098

Chaudhury A, Chander P, Howe PH (2010a) Heterogeneous nuclear ribonucleoproteins (hnRNPs) in cellular processes: focus on hnRNP E1's multifunctional regulatory roles. RNA 16:14491462 
Chaudhury A, Hussey GS, Ray PS, Jin G, Fox PL, Howe PH (2010b) TGF-beta-mediated phosphorylation of hnRNP E1 induces EMT via transcript-selective translational induction of Dab2 and ILEI. Nat Cell Biol 12:286-293

Christofk HR, Vander Heiden MG, Harris MH, Ramanathan A, Gerszten RE, Wei R, Fleming MD, Schreiber SL, Cantley LC (2008) The M2 splice isoform of pyruvate kinase is important for cancer metabolism and tumour growth. Nature 452:230-233

Chung J, Bachelder RE, Lipscomb EA, Shaw LM, Mercurio AM (2002) Integrin (alpha 6 beta 4) regulation of eIF-4E activity and VEGF translation: a survival mechanism for carcinoma cells. J Cell Biol 158:165-174

Collesi C, Santoro MM, Gaudino G, Comoglio PM (1996) A splicing variant of the RON transcript induces constitutive tyrosine kinase activity and an invasive phenotype. Mol Cell Biol 16:5518-5526

Créancier L, Morello D, Mercier P, Prats AC (2000) Fibroblast growth factor 2 internal ribosome entry site (IRES) activity ex vivo and in transgenic mice reveals a stringent tissue-specific regulation. $\mathrm{J}$ Cell Biol 150:275-281

Dales J-P, Beaufils N, Silvy M, Picard C, Pauly V, Pradel V, Formisano-Tréziny $\mathrm{C}$, Bonnier $\mathrm{P}$, Giusiano $\mathrm{S}$, Charpin $\mathrm{C}$ et al (2010) Hypoxia inducible factor 1alpha gene (HIF-1alpha) splice variants: potential prognostic biomarkers in breast cancer. BMC Med 8:44

David CJ, Manley JL (2010) Alternative pre-mRNA splicing regulation in cancer: pathways and programs unhinged. Genes Dev 24:2343-2364

DeFatta RJ, Nathan CO, De Benedetti A (2000) Antisense RNA to eIF4E suppresses oncogenic properties of a head and neck squamous cell carcinoma cell line. Laryngoscope 110:928-933

Di Modugno F, Bronzi G, Scanlan MJ, Del Bello D, Cascioli S, Venturo I, Botti C, Nicotra MR, Mottolese M, Natali PG et al (2004) Human Mena protein, a serex-defined antigen overexpressed in breast cancer eliciting both humoral and CD8+ T-cell immune response. Int J Cancer 109:909-918

Di Modugno F, Mottolese M, Di Benedetto A, Conidi A, Novelli F, Perracchio L, Venturo I, Botti C, Jager E, Santoni A et al (2006) The cytoskeleton regulatory protein hMena (ENAH) is overexpressed in human benign breast lesions with high risk of transformation and human epidermal growth factor receptor-2-positive/ hormonal receptor-negative tumors. Clin Cancer Res 12:1470 1478

Eberle J, Krasagakis K, Orfanos CE (1997) Translation initiation factor eIF-4A1 mRNA is consistently overexpressed in human melanoma cells in vitro. Int J Cancer 71:396-401

Erler JT, Bennewith KL, Nicolau M, Dornhöfer N, Kong C, Le QT, Chi JT, Jeffrey SS, Giaccia AJ (2006) Lysyl oxidase is essential for hypoxia-induced metastasis. Nature 440:1222-1226

Evdokimova V, Ovchinnikov LP, Sorensen PH (2006) Y-box binding protein 1: providing a new angle on translational regulation. Cell Cycle 5:1143-1147

Evdokimova V, Tognon C, Ng T, Ruzanov P, Melnyk N, Fink D, Sorokin A, Ovchinnikov LP, Davicioni E, Triche TJ et al (2009) Translational activation of snaill and other developmentally regulated transcription factors by YB-1 promotes an epithelialmesenchymal transition. Cancer Cell 15:402-415

Fackenthal JD, Godley LA (2008) Aberrant RNA splicing and its functional consequences in cancer cells. Dis Model Mech 1:3742

Ferrara N (1999) Molecular and biological properties of vascular endothelial growth factor. J Mol Med 77:527-543

Fingar DC, Salama S, Tsou C, Harlow E, Blenis J (2002) Mammalian cell size is controlled by mTOR and its downstream targets S6K1 and 4EBP1/eIF4E. Genes Dev 16:1472-1487

Fingar DC, Richardson CJ, Tee AR, Cheatham L, Tsou C, Blenis J (2004) mTOR controls cell cycle progression through its cell growth effectors S6K1 and 4E-BP1/eukaryotic translation initiation factor 4E. Mol Cell Biol 24:200-216

Folkman J, Hanahan D (1991) Switch to the angiogenic phenotype during tumorigenesis. Princess Takamatsu Symp 22:339-347

Forristal CE, Wright KL, Hanley NA, Oreffo RO, Houghton FD (2010) Hypoxia inducible factors regulate pluripotency and proliferation in human embryonic stem cells cultured at reduced oxygen tensions. Reproduction 139:85-97

Fraser D, Wakefield L, Phillips A (2002) Independent regulation of transforming growth factor-betal transcription and translation by glucose and platelet-derived growth factor. Am J Pathol 161:1039-1049

Gardner LB (2010) Nonsense-mediated RNA decay regulation by cellular stress: implications for tumorigenesis. Mol Cancer Res 8:295-308

Ge Y, Zhou F, Chen H, Cui C, Liu D, Li Q, Yang Z, Wu G, Sun S, Gu J et al (2010) Sox2 is translationally activated by eukaryotic initiation factor $4 \mathrm{E}$ in human glioma-initiating cells. Biochem Biophys Res Commun 397:711-717

Genolet R, Rahim G, Gubler-Jaquier P, Curran J (2011) The translational response of the human mdm2 gene in HEK293T cells exposed to rapamycin: a role for the 5'-UTRs. Nucleic Acids Res 39:989-1003

Ghigna C, Giordano S, Shen H, Benvenuto F, Castiglioni F, Comoglio PM, Green MR, Riva S, Biamonti G (2005) Cell motility is controlled by SF2/ASF through alternative splicing of the Ron protooncogene. Molecular cell 20:881-890

Gingras AC, Raught B, Sonenberg N (2001) Regulation of translation initiation by FRAP/mTOR. Genes Dev 15:807-826

Görlach A, Camenisch G, Kvietikova I, Vogt L, Wenger RH, Gassmann M (2000) Efficient translation of mouse hypoxiainducible factor-1alpha under normoxic and hypoxic conditions. Biochim Biophys Acta 1493:125-134

Goswami S, Philippar U, Sun D, Patsialou A, Avraham J, Wang W, Di Modugno F, Nistico P, Gertler FB, Condeelis JS (2009) Identification of invasion specific splice variants of the cytoskeletal protein Mena present in mammary tumor cells during invasion in vivo. Clin Exp Metastasis 26:153-159

Graff JR, Konicek BW, Vincent TM, Lynch RL, Monteith D, Weir SN, Schwier P, Capen A, Goode RL, Dowless MS et al (2007) Therapeutic suppression of translation initiation factor eIF4E expression reduces tumor growth without toxicity. J Clin Invest 117:2638-2648

Greijer AE, van der Groep P, Kemming D, Shvarts A, Semenza GL, Meijer GA, van de Wiel MA, Belien JAM, van Diest PJ, van der Wall E (2005) Up-regulation of gene expression by hypoxia is mediated predominantly by hypoxia-inducible factor 1 (HIF-1). J Pathol 206:291-304

Hanahan D, Weinberg RA (2000) The hallmarks of cancer. Cell 100:57-70

Hanahan D, Weinberg RA (2011) Hallmarks of cancer: the next generation. Cell 144:646-674

Hang X, Li P, Li Z, Qu W, Yu Y, Li H, Shen Z, Zheng H, Gao Y, Wu Y et al (2009) Transcription and splicing regulation in human umbilical vein endothelial cells under hypoxic stress conditions by exon array. BMC Genom 10:126

Harper SJ, Bates DO (2008) VEGF-A splicing: the key to antiangiogenic therapeutics? Nat Rev Cancer 8:880-887

Hay N, Sonenberg N (2004) Upstream and downstream of mTOR. Genes Dev 18:1926-1945

Hennessy BT, Smith DL, Ram PT, Lu Y, Mills GB (2005) Exploiting the PI3K/AKT pathway for cancer drug discovery. Nat Rev Drug Discov 4:988-1004

Hirschfeld M, Zur Hausen A, Bettendorf H, Jager M, Stickeler E (2009) Alternative splicing of Cyr61 is regulated by hypoxia and significantly changed in breast cancer. Cancer Res 69:20822090 
Holcik M, Sonenberg N (2005) Translational control in stress and apoptosis. Nat Rev Mol Cell Biol 6:318-327

Hope NR, Murray GI (2011) The expression profile of RNA-binding proteins in primary and metastatic colorectal cancer: relationship of heterogeneous nuclear ribonucleoproteins with prognosis. Hum Pathol 42:393-402

Houck KA, Ferrara N, Winer J, Cachianes G, Li B, Leung DW (1991) The vascular endothelial growth factor family: identification of a fourth molecular species and characterization of alternative splicing of RNA. Mol Endocrinol 5:1806-1814

Huang Y, Steitz JA (2005) SRprises along a messenger's journey. Molecular cell 17:613-615

Huang C-S, Shen C-Y, Wang H-W, Wu P-E, Cheng C-W (2007) Increased expression of SRp40 affecting CD44 splicing is associated with the clinical outcome of lymph node metastasis in human breast cancer. Clin Chim Acta 384:69-74

Huez I, Créancier L, Audigier S, Gensac MC, Prats AC, Prats H (1998) Two independent internal ribosome entry sites are involved in translation initiation of vascular endothelial growth factor mRNA. Mol Cell Biol 18:6178-6190

Huez I, Bornes S, Bresson D, Créancier L, Prats H (2001) New vascular endothelial growth factor isoform generated by internal ribosome entry site-driven CUG translation initiation. Mol Endocrinol 15:2197-2210

Imai T, Horiuchi A, Wang C, Oka K, Ohira S, Nikaido T, Konishi I (2003) Hypoxia attenuates the expression of E-cadherin via upregulation of SNAIL in ovarian carcinoma cells. Am J Pathol 163:1437-1447

Johannes G, Carter MS, Eisen MB, Brown PO, Sarnow P (1999) Identification of eukaryotic mRNAs that are translated at reduced cap binding complex eIF4F concentrations using a cDNA microarray. Proc Natl Acad Sci U S A 96:13118-13123

Karbowniczek M, Spittle CS, Morrison T, Wu H, Henske EP (2008) mTOR is activated in the majority of malignant melanomas. J Invest Dermatol 128:980-987

Kerekatte V, Smiley K, Hu B, Smith A, Gelder F, De Benedetti A (1995) The proto-oncogene/translation factor eIF4E: a survey of its expression in breast carcinomas. Int J Cancer 64:27-31

Kevil CG, De Benedetti A, Payne DK, Coe LL, Laroux FS, Alexander JS (1996) Translational regulation of vascular permeability factor by eukaryotic initiation factor 4E: implications for tumor angiogenesis. Int J Cancer 65:785-790

Kikuchi H, Pino MS, Zeng M, Shirasawa S, Chung DC (2009) Oncogenic KRAS and BRAF differentially regulate hypoxiainducible factor-1alpha and -2alpha in colon cancer. Cancer Res 69:8499-8506

Kireeva ML, Mo FE, Yang GP, Lau LF (1996) Cyr61, a product of a growth factor-inducible immediate-early gene, promotes cell proliferation, migration, and adhesion. Mol Cell Biol 16:1326-1334

Kornblihtt AR (2007) Coupling transcription and alternative splicing. Adv Exp Med Biol 623:175-189

Kroczynska B, Kaur S, Platanias LC (2009) Growth suppressive cytokines and the AKT/mTOR pathway. Cytokine 48:138-143

Kunz M, Moeller S, Koczan D, Lorenz P, Wenger RH, Glocker MO, Thiesen HJ, Gross G, Ibrahim SM (2003) Mechanisms of hypoxic gene regulation of angiogenesis factor Cyr61 in melanoma cells. J Biol Chem 278:45651-45660

Ladomery MR, Harper SJ, Bates DO (2007) Alternative splicing in angiogenesis: the vascular endothelial growth factor paradigm. Cancer Lett 249:133-142

Lang KJ, Kappel A, Goodall GJ (2002) Hypoxia-inducible factor-1alpha mRNA contains an internal ribosome entry site that allows efficient translation during normoxia and hypoxia. Mol Biol Cell 13:1792-1801

Lazaris-Karatzas A, Montine KS, Sonenberg N (1990) Malignant transformation by a eukaryotic initiation factor subunit that binds to mRNA 5' cap. Nature 345:544-547
Lefave CV, Squatrito M, Vorlova S, Rocco GL, Brennan CW, Holland EC, Pan YX, Cartegni L (2011) Splicing factor hnRNPH drives an oncogenic splicing switch in gliomas. EMBO J.

Lei J, Jiang A, Pei D (1998) Identification and characterization of a new splicing variant of vascular endothelial growth factor: VEGF183. Biochim Biophys Acta 1443:400-406

Leung DW, Cachianes G, Kuang WJ, Goeddel DV, Ferrara N (1989) Vascular endothelial growth factor is a secreted angiogenic mitogen. Science 246:1306-1309

Levy C, Khaled M, Fisher DE (2006) MITF: master regulator of melanocyte development and melanoma oncogene. Trends Mol Med 12:406-414

Lewis TS, Hunt JB, Aveline LD, Jonscher KR, Louie DF, Yeh JM, Nahreini TS, Resing KA, Ahn NG (2000) Identification of novel MAP kinase pathway signaling targets by functional proteomics and mass spectrometry. Mol Cell 6:1343-1354

Li BD, Liu L, Dawson M, De Benedetti A (1997) Overexpression of eukaryotic initiation factor 4E (eIF4E) in breast carcinoma. Cancer 79:2385-2390

Li S, Takasu T, Perlman DM, Peterson MS, Burrichter D, Avdulov S, Bitterman PB, Polunovsky VA (2003) Translation factor eIF4E rescues cells from Myc-dependent apoptosis by inhibiting cytochrome c release. J Biol Chem 278:3015-3022

Li CY, Chu JY, Yu JK, Huang XQ, Liu XJ, Shi L, Che YC, Xie JY (2004a) Regulation of alternative splicing of Bcl-x by IL-6, GMCSF and TPA. Cell research 14:473-479

Li S, Perlman DM, Peterson MS, Burrichter D, Avdulov S, Polunovsky VA, Bitterman PB (2004b) Translation initiation factor 4E blocks endoplasmic reticulum-mediated apoptosis. J Biol Chem 279:2131221317

Liao D, Johnson RS (2007) Hypoxia: a key regulator of angiogenesis in cancer. Cancer Metastasis Rev 26:281-290

Lin MT, Kuo IH, Chang CC, Chu CY, Chen HY, Lin BR, Sureshbabu M, Shih HJ, Kuo ML (2008) Involvement of hypoxia-inducing factor-1alpha-dependent plasminogen activator inhibitor-1 upregulation in Cyr61/CCN1-induced gastric cancer cell invasion. J Biol Chem 283:15807-15815

Liu L, Cash TP, Jones RG, Keith B, Thompson CB, Simon MC (2006) Hypoxia-induced energy stress regulates mRNA translation and cell growth. Mol Cell 21:521-531

Luco RF, Pan Q, Tominaga K, Blencowe BJ, Pereira-Smith OM, Misteli T (2010) Regulation of alternative splicing by histone modifications. Science (New York, NY) 327:996-1000

Luco RF, Allo M, Schor IE, Kornblihtt AR, Misteli T (2011) Epigenetics in Alternative Pre-mRNA Splicing. Cell 144:16-26

Lynch KW (2007) Regulation of alternative splicing by signal transduction pathways. Adv Exp Med Biol 623:161-174

Mamane Y, Petroulakis E, LeBacquer O, Sonenberg N (2006) mTOR, translation initiation and cancer. Oncogene 25:6416-6422

Martin MM, Buckenberger JA, Knoell DL, Strauch AR, Elton TS (2006) TGF-beta(1) regulation of human AT(1) receptor mRNA splice variants harboring exon 2. Mol Cell Endocrinol 249:21-31

Matter N, Herrlich P, König H (2002) Signal-dependent regulation of splicing via phosphorylation of Sam68. Nature 420:691-695

Michlewski G, Sanford JR, Cáceres JF (2008) The splicing factor SF2/ ASF regulates translation initiation by enhancing phosphorylation of 4E-BP1. Molecular cell 30:179-189

Miyagi Y, Sugiyama A, Asai A, Okazaki T, Kuchino Y, Kerr SJ (1995) Elevated levels of eukaryotic translation initiation factor eIF-4E, mRNA in a broad spectrum of transformed cell lines. Cancer Lett 91:247-252

Moller-Levet CS, Betts GNJ, Harris AL, Homer JJ, West CML, Miller CJ (2009) Exon array analysis of head and neck cancers identifies a hypoxia related splice variant of LAMA3 associated with a poor prognosis. PLoS Comput Biol 5:e1000571

Mukudai Y, Kubota S, Eguchi T, Sumiyoshi K, Janune D, Kondo S, Shintani S, Takigawa M (2010) A coding RNA segment that 
enhances the ribosomal recruitment of chicken cen1 mRNA. J Cell Biochem 111:1607-1618

Nasr Z, Robert F, Porco JA Jr, Muller WJ, Pelletier J (2012) eIF4F suppression in breast cancer affects maintenance and progression. Oncogene.

Nathan CO, Carter P, Liu L, Li BD, Abreo F, Tudor A, Zimmer SG, De Benedetti A (1997) Elevated expression of eIF4E and FGF-2 isoforms during vascularization of breast carcinomas. Oncogene 15:1087-1094

Nowak DG, Woolard J, Amin EM, Konopatskaya O, Saleem MA, Churchill AJ, Ladomery MR, Harper SJ, Bates DO (2008) Expression of pro- and anti-angiogenic isoforms of VEGF is differentially regulated by splicing and growth factors. J Cell Sci 121:3487-3495

Nowak DG, Amin EM, Rennel ES, Hoareau-Aveilla C, Gammons M, Damodoran G, Hagiwara M, Harper SJ, Woolard J, Ladomery MR et al (2010) Regulation of Vascular Endothelial Growth Factor (VEGF) splicing from pro-angiogenic to anti-angiogenic isoforms: a novel therapeutic strategy for angiogenesis. J Biol Chem 285:5532-5540

O’Kelly J, Chung A, Lemp N, Chumakova K, Yin D, Wang HJ, Said J, Gui D, Miller CW, Karlan BY et al (2008) Functional domains of $\mathrm{CCN} 1$ (Cyr61) regulate breast cancer progression. Int $\mathrm{J}$ Oncol 33:59-67

O'Reilly KE, Warycha M, Davies MA, Rodrik V, Zhou XK, Yee H, Polsky D, Pavlick AC, Rosen N, Bhardwaj N et al (2009) Phosphorylated 4E-BP1 is associated with poor survival in melanoma. Clin Cancer Res 15:2872-2878

Oltean S, Sorg BS, Albrecht T, Bonano VI, Brazas RM, Dewhirst MW, Garcia-Blanco MA (2006) Alternative inclusion of fibroblast growth factor receptor 2 exon IIIc in Dunning prostate tumors reveals unexpected epithelial mesenchymal plasticity. Proc Natl Acad Sci USA 103:14116-14121

Patel NA, Kaneko S, Apostolatos HS, Bae SS, Watson JE, Davidowitz K, Chappell DS, Birnbaum MJ, Cheng JQ, Cooper DR (2005) Molecular and genetic studies imply Akt-mediated signaling promotes protein kinase CbetaII alternative splicing via phosphorylation of serine/arginine-rich splicing factor SRp40. J Biol Chem 280:14302-14309

Perbal B (2009) Alternative splicing of CCN mRNAs .... it has been upon us. J Cell Commun Signal 3:153-157

Petroulakis E, Mamane Y, Le Bacquer O, Shahbazian D, Sonenberg N (2007) mTOR signaling: implications for cancer and anticancer therapy. Br J Cancer 96:R11-R15

Philippar U, Roussos ET, Oser M, Yamaguchi H, Kim H-D, Giampieri S, Wang Y, Goswami S, Wyckoff JB, Lauffenburger DA et al (2008) A Mena invasion isoform potentiates EGF-induced carcinoma cell invasion and metastasis. Dev Cell 15:813-828

Poltorak Z, Cohen T, Sivan R, Kandelis Y, Spira G, Vlodavsky I, Keshet E, Neufeld G (1997) VEGF145, a secreted vascular endothelial growth factor isoform that binds to extracellular matrix. J Biol Chem 272:7151-7158

Pond AC, Herschkowitz JI, Schwertfeger KL, Welm B, Zhang Y, York B, Cardiff RD, Hilsenbeck S, Perou CM, Creighton CJ et al (2010) Fibroblast growth factor receptor signaling dramatically accelerates tumorigenesis and enhances oncoprotein translation in the mouse mammary tumor virus-Wnt-1 mouse model of breast cancer. Cancer Res 70:4868-4879

Pópulo H, Soares P, Rocha AS, Silva P, Lopes JM (2010) Evaluation of the mTOR pathway in ocular (uvea and conjunctiva) melanoma. Melanoma Res 20:107-117

Postovit L-M, Margaryan NV, Seftor EA, Hendrix MJC (2008) Role of nodal signaling and the microenvironment underlying melanoma plasticity. Pigment Cell Melanoma Res 21:348-357

Primot A, Mogha A, Corre S, Roberts K, Debbache J, Adamski H, Dreno B, Khammari A, Lesimple T, Mereau A et al (2010) ERK- regulated differential expression of the Mitf $6 \mathrm{a} / \mathrm{b}$ splicing isoforms in melanoma. Pigment Cell Melanoma Res 23:93-102

Pritchard-Jones RO, Dunn DBA, Qiu Y, Varey AHR, Orlando A, Rigby H, Harper SJ, Bates DO (2007) Expression of VEGFxxxb, the inhibitory isoforms of VEGF, in malignant melanoma. Br J Cancer 97:223-230

Remy I, Montmarquette A, Michnick SW (2004) PKB/Akt modulates TGF-beta signalling through a direct interaction with Smad3. Nat Cell Biol 6:358-365

Rennel ES, Waine E, Guan H, Schüler Y, Leenders W, Woolard J, Sugiono M, Gillatt D, Kleinerman ES, Bates DO et al (2008) The endogenous anti-angiogenic VEGF isoform, VEGF165b inhibits human tumour growth in mice. Br J Cancer 98:1250-1257

Ria R, Reale A, Castrovilli A, Mangialardi G, Dammacco F, Ribatti D, Vacca A (2010) Angiogenesis and progression in human melanoma. Dermatol Res Pract 2010:185687

Riley A, Jordan LE, Holcik M (2010) Distinct 5' UTRs regulate XIAP expression under normal growth conditions and during cellular stress. Nucleic Acids Res 38:4665-4674

Rofstad EK, Rasmussen H, Galappathi K, Mathiesen B, Nilsen K, Graff BA (2002) Hypoxia promotes lymph node metastasis in human melanoma xenografts by up-regulating the urokinase-type plasminogen activator receptor. Cancer Res 62:1847-1853

Rosenwald IB, Wang S, Savas L, Woda B, Pullman J (2003) Expression of translation initiation factor eIF-2alpha is increased in benign and malignant melanocytic and colonic epithelial neoplasms. Cancer 98:1080-1088

Rousseau D, Gingras AC, Pause A, Sonenberg N (1996) The eIF4Ebinding proteins 1 and 2 are negative regulators of cell growth. Oncogene 13:2415-2420

Schwanhausser B, Busse D, Li N, Dittmar G, Schuchhardt J, Wolf J, Chen W, Selbach M (2011) Global quantification of mammalian gene expression control. Nature 473:337-342

Semenza GL (2003) Targeting HIF-1 for cancer therapy. Nat Rev Cancer 3:721-732

Shapiro IM, Cheng AW, Flytzanis NC, Balsamo M, Condeelis JS, Oktay MH, Burge CB, Gertler FB (2011) An EMT-driven alternative splicing program occurs in human breast cancer and modulates cellular phenotype. PLoS Genet 7:e1002218

Shirakihara T, Horiguchi K, Miyazawa K, Ehata S, Shibata T, Morita I, Miyazono K, Saitoh M (2011) TGF- $\beta$ regulates isoform switching of FGF receptors and epithelial-mesenchymal transition. EMBO J 30:783-795

Shuda M, Kondoh N, Tanaka K, Ryo A, Wakatsuki T, Hada A, Goseki N, Igari T, Hatsuse K, Aihara T et al (2000) Enhanced expression of translation factor mRNAs in hepatocellular carcinoma. Anticancer Res 20:2489-2494

Shultz JC, Goehe RW, Wijesinghe DS, Murudkar C, Hawkins AJ, Shay JW, Minna JD, Chalfant CE (2010) Alternative splicing of caspase 9 is modulated by the phosphoinositide 3-kinase/Akt pathway via phosphorylation of SRp30a. Cancer Res 70:91859196

Sodhi A, Chaisuparat R, Hu J, Ramsdell AK, Manning BD, Sausville EA, Sawai ET, Molinolo A, Gutkind JS, Montaner S (2006) The TSC2/mTOR pathway drives endothelial cell transformation induced by the Kaposi's sarcoma-associated herpesvirus $G$ proteincoupled receptor. Cancer Cell 10:133-143

Srebrow A, Kornblihtt AR (2006) The connection between splicing and cancer. J Cell Sci 119:2635-2641

Stamm S (2002) Signals and their transduction pathways regulating alternative splicing: a new dimension of the human genome. Hum Mol Genet 11:2409-2416

Stein I, Itin A, Einat P, Skaliter R, Grossman Z, Keshet E (1998) Translation of vascular endothelial growth factor mRNA by internal ribosome entry: implications for translation under hypoxia. Mol Cell Biol 18:3112-3119 
Stephens L, Williams R, Hawkins P (2005) Phosphoinositide 3-kinases as drug targets in cancer. Curr Opin Pharmacol 5:357-365

Stoneley M, Willis AE (2004) Cellular internal ribosome entry segments: structures, trans-acting factors and regulation of gene expression. Oncogene 23:3200-3207

Tacconelli A, Farina AR, Cappabianca L, Desantis G, Tessitore A, Vetuschi A, Sferra R, Rucci N, Argenti B, Screpanti I et al (2004) TrkA alternative splicing: a regulated tumor-promoting switch in human neuroblastoma. Cancer Cell 6:347-360

Tan A, Bitterman P, Sonenberg N, Peterson M, Polunovsky V (2000) Inhibition of Myc-dependent apoptosis by eukaryotic translation initiation factor 4E requires cyclin D1. Oncogene 19:1437-1447

Tanaka S, Sugimachi K, Saeki H, Kinoshita J, Ohga T, Shimada M, Maehara Y (2001) A novel variant of WISP1 lacking a Von Willebrand type $\mathrm{C}$ module overexpressed in scirrhous gastric carcinoma. Oncogene 20:5525-5532

Thiery JP, Acloque H, Huang RYJ, Nieto MA (2009) Epithelialmesenchymal transitions in development and disease. Cell 139:871-890

Thomassen M, Blanco A, Montagna M, Hansen TV, Pedersen IS, Gutierrez-Enriquez S, Menendez M, Fachal L, Santamarina M, Steffensen AY, et al (2011) Characterization of BRCA1 and BRCA2 splicing variants: a collaborative report by ENIGMA consortium members. Breast Cancer Res Treat.

Tischer E, Mitchell R, Hartman T, Silva M, Gospodarowicz D, Fiddes JC, Abraham JA (1991) The human gene for vascular endothelial growth factor. Multiple protein forms are encoded through alternative exon splicing. J Biol Chem 266:11947-11954

Uniacke J, Holterman CE, Lachance G, Franovic A, Jacob MD, Fabian MR, Payette J, Holcik M, Pause A, Lee S (2012) An oxygenregulated switch in the protein synthesis machinery. Nature 486:126-129

Vagner S, Gensac MC, Maret A, Bayard F, Amalric F, Prats H, Prats AC (1995) Alternative translation of human fibroblast growth factor 2 mRNA occurs by internal entry of ribosomes. Mol Cell Biol 15:35-44

Valacca C, Bonomi S, Buratti E, Pedrotti S, Baralle FE, Sette C, Ghigna C, Biamonti G (2010) Sam68 regulates EMT through alternative splicing-activated nonsense-mediated mRNA decay of the SF2/ASF proto-oncogene. J Cell Biol 191:87-99

Villanueva J, Herlyn M (2008) Melanoma and the tumor microenvironment. Curr Oncol Rep 10:439-446

Wagner JA (1991) The fibroblast growth factors: an emerging family of neural growth factors. Curr Top Microbiol Immunol 165:95118

Wang WB, Boing S, Zhou XQ, Ji P, Dong Y, Yao Q, Muller-Tidow C (2002) Identification of metastasis-associated genes in early stage non-small cell lung cancer by subtractive hybridization. Sheng Wu Hua Xue Yu Sheng Wu Wu Li Xue Bao (Shanghai) 34:273278

Wang W, Goswami S, Lapidus K, Wells AL, Wyckoff JB, Sahai E, Singer RH, Segall JE, Condeelis JS (2004) Identification and testing of a gene expression signature of invasive carcinoma cells within primary mammary tumors. Cancer Res 64:8585-8594

Wang W, Wyckoff JB, Goswami S, Wang Y, Sidani M, Segall JE, Condeelis JS (2007) Coordinated regulation of pathways for enhanced cell motility and chemotaxis is conserved in rat and mouse mammary tumors. Cancer Res 67:3505-3511

Wang ET, Sandberg R, Luo S, Khrebtukova I, Zhang L, Mayr C, Kingsmore SF, Schroth GP, Burge CB (2008) Alternative isoform regulation in human tissue transcriptomes. Nature 456:470-476

Wang X, Zhao Y, Xiao Z, Chen B, Wei Z, Wang B, Zhang J, Han J, Gao Y, Li L et al (2009) Alternative translation of OCT4 by an internal ribosome entry site and its novel function in stress response. Stem Cells 27:1265-1275

Warzecha CC, Sato TK, Nabet B, Hogenesch JB, Carstens RP (2009a) ESRP1 and ESRP2 are epithelial cell-type-specific regulators of FGFR2 splicing. Mol Cell 33:591-601

Warzecha CC, Shen S, Xing Y, Carstens RP (2009b) The epithelial splicing factors ESRP1 and ESRP2 positively and negatively regulate diverse types of alternative splicing events. RNA Biol 6:546-562

Watermann DO, Tang Y, Zur Hausen A, Jäger M, Stamm S, Stickeler E (2006) Splicing factor Tra2-beta1 is specifically induced in breast cancer and regulates alternative splicing of the CD44 gene. Cancer Res 66:4774-4780

Wen F, Shen A, Shanas R, Bhattacharyya A, Lian F, Hostetter G, Shi J (2010) Higher expression of the heterogeneous nuclear ribonucleoprotein k in melanoma. Ann Surg Oncol 17:2619-2627

White ES, Sagana RL, Booth AJ, Yan M, Cornett AM, Bloomheart CA, Tsui JL, Wilke CA, Moore BB, Ritzenthaler JD et al (2010) Control of fibroblast fibronectin expression and alternative splicing via the PI3K/Akt/mTOR pathway. Exp Cell Res 316:2644 2653

Winter SC, Buffa FM, Silva P, Miller C, Valentine HR, Turley H, Shah KA, Cox GJ, Corbridge RJ, Homer JJ et al (2007) Relation of a hypoxia metagene derived from head and neck cancer to prognosis of multiple cancers. Cancer Res 67:3441-3449

Woolard J, Wang W-Y, Bevan HS, Qiu Y, Morbidelli L, PritchardJones RO, Cui T-G, Sugiono M, Waine E, Perrin R et al (2004) VEGF165b, an inhibitory vascular endothelial growth factor splice variant: mechanism of action, in vivo effect on angiogenesis and endogenous protein expression. Cancer Res 64:7822-7835

Wouters BG, Koritzinsky M (2008) Hypoxia signalling through mTOR and the unfolded protein response in cancer. Nat Rev Cancer $8: 851-864$

Yan G, Fukabori Y, McBride G, Nikolaropolous S, McKeehan WL (1993) Exon switching and activation of stromal and embryonic fibroblast growth factor (FGF)-FGF receptor genes in prostate epithelial cells accompany stromal independence and malignancy. Mol Cell Biol 13:4513-4522

Yang SX, Hewitt SM, Steinberg SM, Liewehr DJ, Swain SM (2007) Expression levels of eIF4E, VEGF, and cyclin D1, and correlation of eIF4E with VEGF and cyclin D1 in multi-tumor tissue microarray. Oncol Rep 17:281-287

Yin JY, Dong Z, Liu ZQ, Zhang JT (2011) Translational control gone awry: a new mechanism of tumorigenesis and novel targets of cancer treatments. Biosci Rep 31:1-15

Young RM, Wang SJ, Gordan JD, Ji X, Liebhaber SA, Simon MC (2008) Hypoxia-mediated selective mRNA translation by an internal ribosome entry site-independent mechanism. J Biol Chem 283:16309-16319 